\title{
Achieving excellence in private intensive care units: The effect of transformational leadership and organisational culture on organisational change outcomes
}

\author{
Authors: \\ Portia J. Jordan ${ }^{1}$ \\ Amanda Werner ${ }^{2}$ \\ Danie Venter ${ }^{3}$ \\ Affiliations: \\ ${ }^{1}$ Department of Nursing \\ Science, Nelson Mandela \\ Metropolitan University, \\ South Africa \\ ${ }^{2}$ Department of Human \\ Resource Management, \\ Nelson Mandela \\ Metropolitan University, \\ South Africa \\ ${ }^{3}$ Unit for Statistical \\ Consultation, Nelson \\ Mandela Metropolitan \\ University, South Africa \\ Correspondence to: \\ Portia Jordan \\ Email: \\ portia.jordan@nmmu.ac.za \\ Postal address: \\ PO BOX 77000, Nelson \\ Mandela Metropolitan \\ University, Port Elizabeth \\ 6031, South Africa

\section{Dates:} \\ Received: 27 Apr. 2015 \\ Accepted: 04 Sept. 2015 \\ Published: 02 Dec. 2015 \\ How to cite this article: \\ Jordan, P.J., Werner, A., \& \\ Venter, D. (2015). Achieving \\ excellence in private \\ intensive care units: The \\ effect of transformational \\ leadership and organisational \\ culture on organisational \\ change outcomes. SA \\ Journal of Human Resource \\ Management/SA Tydskrif vir \\ Menslikehulpbronbestuur, \\ 13(1), Art. \#707, 10 pages. \\ http://dx.doi.org/10.4102/ \\ sajhrm.v13i1.707
}

Read online:
Orientation: Organisational change outcomes in private intensive care units are linked to higher patient satisfaction, improved quality of patient care, family support, cost-effective care practices and an increased level of excellence. Transformational leadership and fostering a positive organisational culture can contribute to these change outcomes.

Research purpose: The study determined whether transformational leadership and a supportive organisational culture were evident in six private intensive care units in the Eastern Cape, South Africa. A conceptual framework to investigate the relationship between transformational leadership, organisational culture, and organisational change outcomes, was proposed and tested.

Motivation for the study: The prevalence of transformational leadership, a positive organisational culture and their effect on organisational change outcomes in private healthcare industries require further research in order to generate appropriate recommendations.

Research design, approach and method: A positivistic, quantitative design was used. A survey was conducted using a questionnaire which, in previous studies, produced scores with Cronbach's alpha coefficients greater than 0.80, to collect data from a sample of 130 professional nurses in private intensive care units.

Main findings: Transformational leadership and a positive organisational culture were evident in the private intensive care units sampled. A strong, positive correlation exists between transformational leadership, organisational culture, and organisational change outcomes. This correlation provides sufficient evidence to accept the postulated research hypotheses. Innovation and intellectual stimulation were identified as the factors in need of improvement.

Practical or managerial implications: The findings of the study may be used by managers in intensive care units to promote organisational change outcomes, linked to transformational leadership and a positive organisational culture.

Contribution: The study provides evidence of the way in which transformational leadership and a positive organisational culture affect organisational change outcomes in the context of private healthcare in South Africa, thereby addressing a research gap in this area.

\section{Introduction}

Organisational culture is often seen as either the key issue or the most significant element in organisational change efforts. A positive organisational culture in healthcare industries has a significant impact on the quality of care, patient safety, teamwork, innovation and professional development of healthcare professionals (Alharbi, Olsson, Ekman \& Carlström, 2014; Korbangyang \& Ussahawanitchakit, 2009; Kwahk \& Lee, 2008). Organisational culture should, however, not be viewed in isolation. In fact, organisational culture and leadership are seen as intertwined. The relationship between the two concepts represents an on-going interplay in which the leader shapes the culture and is in turn shaped by the culture. Effective leaders make cultures, and their fundamental role is to affect others and to make changes that increase organisational efficiency and performance (Birinci \& Y1ldırım, 2013). In healthcare, transformational leadership is identified as the leadership style that can lead to change, guide good clinical decision-making, encourage innovation, enhance patient-centred care and ultimately lead to organisational effectiveness and change.

The South African healthcare industry comprises private and public healthcare institutions. Although the ultimate focus of both types of institution is to be a service provider for patients admitted to and treated at the institutions, the operations of the two sectors differ. Owing to the

Copyright: @ 2015. The Authors. Licensee: AOSIS OpenJournals. This work is licensed under the Creative Commons Attribution License. 
drive for cost-effective care, increased customer satisfaction and the need for financial performance, the private healthcare industry has different objectives, and therefore requires a different leadership style and organisational culture than the public healthcare sector. The first phase of the study focussed on the private healthcare sector, and therefore this article will only report on the findings as derived from the data collected in the private healthcare sector. Data findings from the public sector will follow in a future article.

Healthcare comprises different levels of care, for instance, acute care, rehabilitative care, emergency care or outpatient clinics. Due to the extent of these different units, it was decided to focus only on the intensive care units. The research focused on the prevalence of the relationship between organisational culture, transformational leadership, and organisational change outcomes, in private intensive care units in the Eastern Cape Province.

\section{Literature review Healthcare in South Africa}

The healthcare system globally, as well as in South Africa, is constantly changing, complex and turbulent. Such a climate is characterised by a cost- and time-constrained work environment, a shortage of healthcare workers, increased patient acuity, a quest for evidence and best practices, and the challenge of achieving desired patient outcomes (Casida \& Pinto-Zipp, 2008).

Leaders in healthcare must have innovative strategies in order to motivate staff members to go beyond their selfinterest for the good of the patients and to improve the organisation and staff performance. These innovative strategies might include the use of clinical practice guidelines, the use of information technology or new policies guiding patient care decisions. Despite these difficulties, these strategies must result in high quality, cost-effective patient care, accompanied by high levels of patient satisfaction. Improvement of patient services is regarded as one of the goals of leadership in a healthcare organisation. Leaders should focus on a leadership style that promotes innovation, where best-demonstrated practices can be adopted to help healthcare practitioners to work smarter, faster and better (Thakur, Hsu \& Fontenot, 2012). Utilising a transformational leadership style and having an effective organisational culture are strategies that can assist healthcare managers in achieving these goals, as well as addressing the challenges of the current healthcare climate (Tourangeu \& McGilton, 2004).

Private healthcare organisations are continuously adopting new programmes, and changing their existing practices in order to improve effectiveness and efficiency in patient care and service delivery (Mitchell, 2013). If change is not adopted, especially in private healthcare institutions, business performance, competitive advantage, patient care, customer satisfaction, and the attraction and retention of customers, may be negatively influenced and can be detrimental to the profitability and sustainability of the business (Jandaghi, Martin \& Farjarmi, 2009; Korbangyang \& Ussahawanitchakit, 2009).

The rising cost of healthcare treatment, shortages of healthcare professionals, advances in healthcare sciences, technology demands, economic pressure, the need for cost-effective and quality care, and the need to harness and maintain the competitive advantage, are factors that encourage leaders to reflect on and change practices where needed in healthcare organisations (Craig \& Smyth, 2012; Gilley, McMillian \& Gilley, 2009; Mitchell, 2013). In order to achieve excellence in such an environment, leaders continuously need to review their leadership style and the organisational culture (Mitchell, 2013; Parmelli et al., 2011; Wong \& Cummings, 2007).

Healthcare systems are being challenged to provide quality and cost-effective care to the population of the world. South Africa is no different, but it has the added problem of a dual healthcare system. The public sector comprises government healthcare institutions which provide free healthcare to a mostly impoverished population, whilst the private sector consists of profit-seeking organisations and individuals who serve a population that can either afford medical insurance or are self-paying (Klopper, Coetzee, Pretorius \& Bester, 2012). The private healthcare sectors are large industries, providing employment for many people and facilitating significant economic activity, which affects many more patients and role players directly participating in the use and provision of private health services (Econex, 2013). For these reasons it is important that the organisational culture and leadership are optimised, in order to promote productivity, performance, and change.

There appears to be a paucity of literature available on transformational leadership, organisational culture and change, related to the South African private healthcare industry. It is therefore important to investigate the prevalence of transformational leadership and culture, and whether there is a relationship between these variables and organisational change outcomes in private intensive care units. This study focused on intensive care units, which are specialised areas in a healthcare organisation, where critically ill patients are admitted and cared for (Craig \& Smyth, 2012; Robbins \& Davidhizar, 2007; Urden, Stacy \& Lough, 2014).

\section{Transformational leadership}

Transformational leadership is defined as a leadership approach that triggers change in individuals and social systems. In its ideal form, transformational leadership creates valuable and positive change in followers, with the end goal of developing followers into leaders. Transformational leaders expose a new route for improvement and progress by generating new ideas and perspectives. They change their followers, empower them to develop, and create new needs, tendencies and values, which encourage followers to grow, develop and change into a new generation of leaders. In order to optimise transformational leadership, innovation should be the core focus (Bass \& Riggio, 2006; Hough, Arthur, Thompson, Strickland \& Gamble, 2011; Jandaghi et al., 2009). 
According to Bass and Avolio (2000), transformational leadership has four dimensions:

- idealised influence of charisma

- inspirational motivation

- individualised consideration

- intellectual stimulation. Idealised influence of charisma involves the formulation and articulation of visions.

A vision is defined as the future strategic course, or the direction in which the individual or company is heading (Hough et al., 2011). Inspirational motivation is the way that leaders motivate and inspire followers to commit to the vision of the organisation. Leaders with an inspirational motivation foster strong team spirit as a means for leading team members towards achieving the desired goals (Bass \& Riggio, 2006). Individualised consideration refers to the leaders paying special attention to each individual's need for achievement and growth by acting as a coach or mentor. Intellectual stimulation refers to the way leaders motivate and inspire their followers to be innovative and creative (Bass \& Riggio, 2006).

Transformational leadership should be regarded as an important aspect to transform and change care delivery outcomes in the healthcare industry (Robbins \& Davidhizar, 2007). In a study conducted in 1300 hospitals across the United States and Europe, it was found that well-managed hospitals with clinically qualified leaders produced a higher standard of patient care, thus emphasising the importance of good leadership (Dorgan et al., 2010). Workforce surveys amongst healthcare workers in the United Kingdom have shown that the higher the leadership quality of senior managers (as rated by staff), the higher the rate of organisational performance and the lower the number of patient complaints (Care Quality Commission, 2011). Having a transformational leadership style in the healthcare industry is pivotal because it will ultimately contribute to quality patient care and improved organisational outcomes, especially in private healthcare where quality and efficient care are cost drivers (Jandaghi et al., 2009).

\section{Organisational culture}

Organisational culture is an important aspect to consider in any organisation. A universally adopted definition provided by Schein (1997) is that organisational culture is a pattern of shared basic assumptions that were learned by a group as it solved its problems of external adaptation and internal integration. Culture can be viewed as a lens through which an organisation can be understood and interpreted (Parmelli et al., 2011). Werner et al. (2012) concur in stating that 'organisational culture' refers to a system of shared assumptions or meanings held by members that distinguishes one organisation from others.

Organisational culture in healthcare is important as it helps healthcare professionals to establish a learning environment that promotes professional development and enhances teamwork. The culture in healthcare must promote teamwork and values, and supports team members and their opinions. Furthermore, excellence and quality patient care is promoted, change enabled, and smoother implementation of change processes are allowed, which are critical for the success of healthcare organisations (Acar \& Acar, 2012). A study done by Carney (2011) found that excellence in patient care delivery that is allied to positive value systems and utilising strategic involvement were the most important organisational cultural influences required for optimum effectiveness in quality care delivery. Acar and Acar (2012) observe that organisational culture has increasingly been seen as an important consideration in healthcare reform. They argue that ultimately innovation and organisational change cannot happen unless there is a culture conducive to change. An innovative culture promotes learning, (either by means of in-service learning, or professional development) and encourages innovative care practices, or care practices.

\section{Organisational change outcomes}

There is a significant relationship between organisational culture and organisational change outcomes, such as increased financial performance, gaining a competitive advantage, organisational performance, improved patient care delivery and satisfaction, more efficient and cost-effective care practices, and enhanced family support (Acar \& Acar, 2012).

Organisational change outcomes can include enhanced innovation, engaged employees, increased motivation and confidence, encouragement of employers to think creatively and reflectively, improved problem-solving abilities, and a positive approach to learning innovative practices (Hsiao, Chang \& Tu, 2012; Yildirim \& Birinci, 2013). Werner et al. (2012) indicate quality, efficiency and effectiveness, and customer and employee satisfaction as outcomes of organisational change.

Transformational leadership and organisational culture can assist in pioneering change and establishing positive change outcomes. Caldwell, Chatman, O'Reilly, Ormiston and Lapiz (2008) concur that effective leadership that focuses on transformation contributes to positive change outcomes which are linked to higher patient satisfaction and ultimately improved patient care. Effective leadership is also associated with support for change and change readiness. Hence, it can be concluded that transformational leadership and a positive organisational culture contribute to organisational change outcomes that are beneficial for organisations, including those in the healthcare industry.

\section{Proposed conceptual framework and hypothesis formulation}

Against the background of the preceding literature, a conceptual framework was developed (Figure 1). The conceptual framework illustrates the relationship between the independent variables, namely transformational leadership and organisational culture, and the dependent variable, namely organisational change outcomes. The model assumes that the two independent variables are positively 


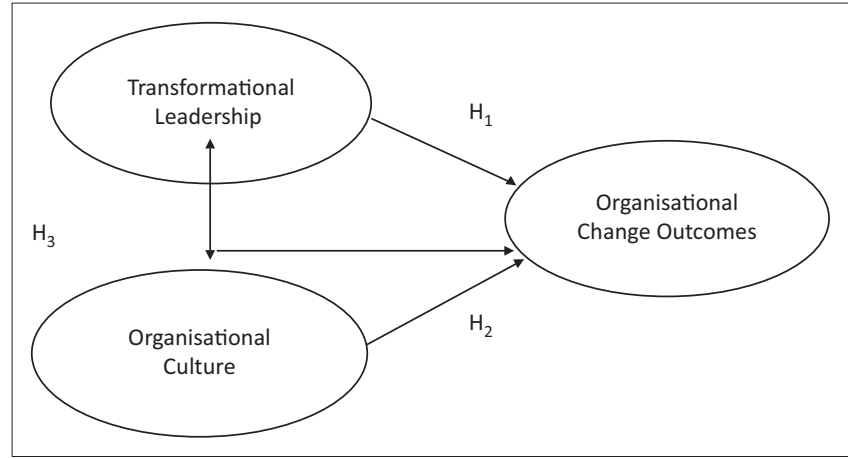

Source: P.J. Jordan

FIGURE 1: Theoretical model.

associated with organisational change outcomes. The research hypotheses derived from the model are as follows:

- Hypothesis 1: There is a significant positive relationship between transformational leadership and organisational change outcomes.

- Hypothesis 2: There is a significant positive relationship between organisational culture and organisational change outcomes.

- Hypothesis 3: There is a significant positive relationship between organisational culture, transformational leadership and organisational change outcomes. The hypothesised relationships are depicted in Figure 1.

\section{Method}

\section{Research approach}

A positivistic, quantitative research design was used in the study.

\section{Sampling and study participants}

The research population consisted of 180 professional nurses in the six intensive care units in the private hospitals in the Eastern Cape. A convenience sampling method was used, where the most readily accessible persons were asked to participate in the study (Burns \& Grove, 2013). All professional nurses who worked in the adult intensive care units and who were willing to participate in the study, were included. See Table 1 for a layout of the population.

Of the 180 questionnaires distributed, 130 were completed and returned, showing a response rate of $72 \%$.

\section{Measuring instruments}

Data was collected by means of a questionnaire, which included open-ended as well as fixed-response items with a 5 point Likert scale ranging from (1) strongly disagree to (5) strongly agree. The questionnaire items, specifically the terminologies related to healthcare were adapted for the purpose of the study. The questionnaire measured the following:

- Demographic data: Four items assessed the demographic profile (age, gender, position and years worked in the intensive care unit) of the participants, using nominal and ordinal scales.
TABLE 1: Population of professional nurses in private intensive care units in Nelson Mandela Bay and Buffalo City.

\begin{tabular}{llcc}
\hline Geographical area & Region & \multicolumn{2}{c}{ Population } \\
\cline { 3 - 4 } & & $\boldsymbol{N}$ & $\mathbf{\%}$ \\
\hline East London & Hospital A & 20 & 11 \\
& Hospital B & 12 & 7 \\
& Hospital C & 45 & 25 \\
\multirow{2}{*}{ Nelson Mandela Bay } & Hospital A & 48 & 27 \\
& Hospital B & 40 & 22 \\
& Hospital C & 15 & 8 \\
\hline Total & & $\mathbf{1 8 0}$ & $\mathbf{1 0 0}$ \\
\hline
\end{tabular}

- Organisational culture: Fourteen items were based on data derived from studies that explored organisational culture in healthcare (Carney, 2011; Hsiao et al., 2012; Scott, Mannion, Davies \& Marshall, 2003). The constructs derived from the literature and used in the questionnaire included teamwork, innovation, patient care and professional development and was specifically contextualised to organisational culture in healthcare.

- Transformational leadership: A 12-item measurement was based on the transformational leadership model of Bass and Alvoloi (2000). Transformational leadership has four dimensions: (1) idealised influence of charisma; (2) inspirational motivation; (3) individualised consideration; and (4) intellectual stimulation.

- Organisational change outcomes: A15-item measurement based on the frameworks of Ramachandran (2013), Weiner (2009) and Werner et al. (2012) was used. Patient, family and staff related issues, as well as organisational care practices were the constructs used in the questionnaire. These constructs were based on the change outcomes that should be evident in healthcare if transformational and organisational cultures are prevalent.

\section{Ethical considerations}

Prior to data collection, ethical clearance was granted by the institutional academic ethics committee (H14-BESHRM-058). In order to ensure that ethical principles were adhered to, ethical clearance was requested. Permission was also granted by the healthcare ethics committees and hospital and unit managers where the study was conducted. Participant consent was obtained prior to commencing with the study.

\section{Data Collection procedure}

Questionnaires were distributed by the researcher, with the assistance of three trained fieldworkers, at the beginning of each day and during night shift. Where practically possible, the researcher remained in the unit for 10-15 min at the beginning of the data collection process. The researcher collected the questionnaires, which were placed in a sealed box, at a pre-arranged time and date, by the unit managers. The data collection process continued over a period of 5 weeks, May - July 2014, which enabled the professional nurses on all the shifts to be included in the study. 


\section{Reliability and validity of the study}

The Cronbach's alpha coefficient was used to calculate the internal consistency of the measuring scales. The results are reported in Table 2. From these results it can be concluded that the scores derived from the instrument were very reliable, as a score of 0.80 or higher was obtained for all the factors, with transformational leadership obtaining the highest score of 0.97 .

Validity refers to the extent to which a questionnaire measures what it is supposed to measure, by obtaining data relevant to the constructs being measured. Content validity concerns the representativeness of the questions used in the data instrument (Scott \& Mazhindu, 2014). Questionnaires were submitted to four experts in the field of critical care and management in health, and they confirmed that the questionnaire had the required content validity. Face validity was obtained by asking a critical care healthcare practitioner to assess the questions for accuracy. The statistician reviewed the questionnaire in terms of its format, layout, and whether the type of questions were suitable for statistical analysis. A pilot study with five participants was conducted to further ensure the validity and reliability of the questionnaire. No changes to the measuring instrument were indicated by the pilot study participants.

\section{Data analysis}

Statistica version 12 was used to analyse the data. Descriptive statistical analyses by means of frequency distributions were used to analyse the demographic data. Pearson's product-moment correlations were calculated to quantify the relationships between the scales and subscales of the dependent and independent variables. Multiple linear regression analysis was done to investigate the relationship between the dependent and independent variables. The statistical analysis tools provided a basis for testing the hypotheses. The required level of statistical significance $(\alpha)$ was set at 0.05 .

\section{Results}

\section{Demographic characteristics}

The sample group consisted of mostly females (94\%), between 31 and 50 years of age $(63 \%)$, with less than ten years' work

TABLE 2: Cronbach's alpha coefficients for the factors or subscales.

\begin{tabular}{lc}
\hline Factors & Cronbach's alpha \\
\hline Transformational Leadership (TL) & 0.97 \\
L1 Idealised influence of charisma & 0.91 \\
L2 Inspirational motivation & 0.94 \\
L3 Individualised consideration & 0.81 \\
L4 Intellectual stimulation & 0.93 \\
Organisational Culture (OC) & 0.86 \\
OC1 Teamwork & 0.80 \\
OC2 Innovation & 0.84 \\
OC3 Patient care & 0.84 \\
OC4 Professional development & 0.81 \\
Organisational Change Outcomes (OCO) & 0.90 \\
OCO1 Patient and family satisfaction & 0.84 \\
OCO2 Innovative and collaborative staff practices & 0.93 \\
OCO3 Organisational effectiveness and change & 0.90 \\
\hline
\end{tabular}

OC, Organisational Culture; L, Leadership; OCO, Organisational Change Outcomes.
TABLE 3: Demographic profile of the sample group.

\begin{tabular}{llcc}
\hline Category & Variable & $\boldsymbol{n}$ & Percentage \\
\hline Gender & Female & 122 & 94 \\
& Male & 8 & 6 \\
Age & $<5$ years & 5 & 4 \\
& $25-30$ years & 8 & 6 \\
& $31-40$ years & 36 & 28 \\
& $41-50$ years & 45 & 35 \\
& $51-60$ years & 30 & 23 \\
Years working in the & 61-65 years & 6 & 5 \\
intensive care unit & $<1$ year & 22 & 17 \\
& $1-4$ years & 27 & 21 \\
& $5-9$ years & 35 & 27 \\
& $10-19$ years & 23 & 18 \\
& $>20$ years & 23 & 18 \\
Position held in the & $\begin{array}{l}\text { Permanently } \\
\text { employed nurses }\end{array}$ & 109 & 84 \\
intensive care unit & Agency appointed & 21 & 16 \\
& nurses & & \\
\hline
\end{tabular}

$n=130$.

experience in intensive care units $(65 \%)$ and permanently employed (84\%). Table 3 presents the demographic profile of the sample group.

\section{Prevalence of transformational leadership, organisational culture and organisational change outcomes}

The findings of the study, as illustrated in Table 4, revealed that organisational culture had the highest mean score $(\mathrm{M}=3.99 ; \mathrm{SD}=0.63)$ followed by leadership $(\mathrm{M}=3.86$; $\mathrm{SD}=0.96)$ and organisational change outcomes $(\mathrm{M}=3.85$; $\mathrm{SD}=0.61$. The mean scores for these three variables are all in the positive range (3.4-4.2) of the 5-point Likert scale that was utilised in the questionnaire. The results showed that transformational leadership, organisational culture and organisational change outcomes were prevalent in the private intensive care units.

Although the subscales results were positive, it should be noted that the following scored the lowest:

- Innovation ( $\mathrm{M}=3.83 ; \mathrm{SD}=0.73)$.

- Intellectual stimulation ( $\mathrm{M}=3.73 ; \mathrm{SD}=1.00)$.

- Organisational effectiveness $(\mathrm{M}=3.74 ; \mathrm{SD}=0.70)$.

\section{Pearson correlation analysis}

Pearson's product-moment correlations (Table 5) were calculated in order to identify significant relations between scales and subscales for transformational leadership, culture, and organisational change outcomes. Correlations were all significant (both statistically because all $r>0.172$ and practically because all $r>0.300$ ) and positive, ranging from 0.428 to 0.976 with 84 out of 91 correlations $(92.3 \%)$ being strong correlations $(r>0.500)$. Smallest value is 0.428 with most of the relationships that can be described as strong $(r>0.50)$.

The results suggest a significant and positive relationship between transformational leadership, organisational culture, and organisational change outcomes. 
TABLE 4: Measures of central tendency and dispersion - Transformational leadership, organisational culture and change outcomes.

\begin{tabular}{|c|c|c|c|c|c|c|c|c|}
\hline Factors & Items & Mean & S.D. & Minimum & Quartile 1 & Median & Quartile 3 & Maximum \\
\hline \multirow[t]{5}{*}{ Transformational leadership } & Idealised influence of charisma & 3.92 & 0.97 & 1.00 & 3.33 & 4.00 & 4.67 & 5.00 \\
\hline & Inspirational motivation & 3.91 & 1.01 & 1.00 & 3.50 & 4.00 & 5.00 & 5.00 \\
\hline & Individualised consideration & 3.89 & 0.99 & 1.00 & 3.50 & 4.00 & 4.50 & 5.00 \\
\hline & Intellectual stimulation & 3.73 & 1.00 & 1.00 & 3.50 & 4.00 & 4.25 & 5.00 \\
\hline & Transformational Leadership factors combined & 3.86 & 0.96 & 1.00 & 3.65 & 4.00 & 4.56 & 5.00 \\
\hline \multirow[t]{5}{*}{ Organisational culture } & Teamwork & 4.20 & 0.74 & 1.33 & 4.00 & 4.33 & 4.67 & 5.00 \\
\hline & Innovation & 3.83 & 0.73 & 2.00 & 3.33 & 4.00 & 4.33 & 5.00 \\
\hline & Patient care & 3.96 & 0.71 & 2.00 & 3.60 & 4.00 & 4.60 & 5.00 \\
\hline & Professional development & 3.97 & 0.73 & 1.50 & 3.50 & 4.00 & 4.50 & 5.00 \\
\hline & Organisational Culture factors combined & 3.99 & 0.63 & 2.00 & 3.62 & 4.07 & 4.44 & 5.00 \\
\hline \multirow[t]{4}{*}{ Change outcomes } & Patient and family satisfaction & 3.97 & 0.63 & 2.00 & 4.00 & 4.00 & 4.00 & 5.00 \\
\hline & Innovative and collaborative staff practices & 3.82 & 0.65 & 1.78 & 3.44 & 3.78 & 4.22 & 5.00 \\
\hline & Organisational effectiveness & 3.74 & 0.70 & 1.00 & 3.33 & 3.67 & 4.17 & 5.00 \\
\hline & Change Outcomes factors combined & 3.85 & 0.61 & 1.59 & 3.46 & 3.83 & 4.24 & 5.00 \\
\hline
\end{tabular}

\section{Multiple linear regression analysis}

Multiple linear regression analysis was conducted to investigate the multivariate relationship between independent variables, namely transformational leadership, organisational culture and dependent variable namely organisational change outcomes in private intensive care units.

The linear regression model tested was:

$\mathrm{OCO}=\alpha+\beta_{1} \mathrm{OC}+\beta_{2} \mathrm{TL}+\varepsilon$ where: OCO is Organisational Change Outcomes; OC is Organisational Culture; and TL is Transformational Leadership. The results are summarised in Table 6.

Table 6 shows that the multiple $R^{2}$ of 0.526 indicates that $52.6 \%$ of the variation in organisational change outcomes was accounted for by variation in organisational culture and transformational leadership. The relationships were statistically significant as the $t$-test $p$ values were all less than 0.05. Thepositivecoefficientsimply that positiveorganisational culture and transformational leadership results in positive organisational change outcomes in an organisation. The results provide proof of a significant relationship between organisational culture and transformational leadership, and organisational change outcomes in private intensive care units in the Eastern Cape.

\section{Discussion}

\section{Transformational leadership}

The findings suggest that transformational leadership is prevalent within private intensive care units in the Eastern Cape. However, it should be noted that the subscale on intellectual stimulation scored the lowest within this domain. Transformational leadership has strong positive correlations with organisational culture $(r=0.781 ; p<0.05)$ and organisational change outcomes $(r=0.658 ; p<0.05)$. Transformational leadership is also a statistically significant predictor of organisational change outcomes $(\beta=0.2624$; $t=2.67 ; p=0.008)$. The positive and significant correlation between transformational leadership and organisational change outcomes therefore supports the acceptance of Hypothesis 1 in this study.

Transformational leaders are seen as charismatic, optimistic and open to the viewpoints of others. They help to formulate and articulate the vision of the organisation, they are willing to take risks, and demonstrate high standards of ethical and moral conduct. Transformational leaders have an inspirational motivation that fosters a strong team spirit. These leaders encourage subordinates and acknowledge individual differences in the team, so that team members can take on more responsibility, become empowered and are able to share work-related knowledge. These leaders give supportive leadership and are able to recognise individual achievements. Transformational leaders in healthcare contribute to the quality of patient care delivery, enhanced patient safety, increased patient and family satisfaction and organisational effectiveness (DuBrin, 2013; Eisenbeiss \& Boerner, 2013; Garci'a-Morales, Llore'ns-Montes \& VerdúJover, 2008; Malloy \& Penprase, 2010; Wong \& Cummings, 2007). Transformational leadership within intensive care units can thus contribute to achieving excellence in healthcare.

Intellectual stimulation (lowest scored subscale) refers to the way leaders inspire innovation and creativity amongst their followers. Transformational leaders encourage followers to question their assumptions, try out new approaches or methods to solve old problems, and to be innovative in new treatment options, technology or other care modalities (Bass \& Riggio, 2006). Based on the findings, it is recommended that leaders should encourage intellectual stimulation amongst the nurses in the intensive care units, as it can strengthen the current leadership present.

\section{Organisational culture}

The findings suggest that organisational culture is prevalent within the private intensive care units in the Eastern Cape. However, it should be noted that the subscale on innovation 


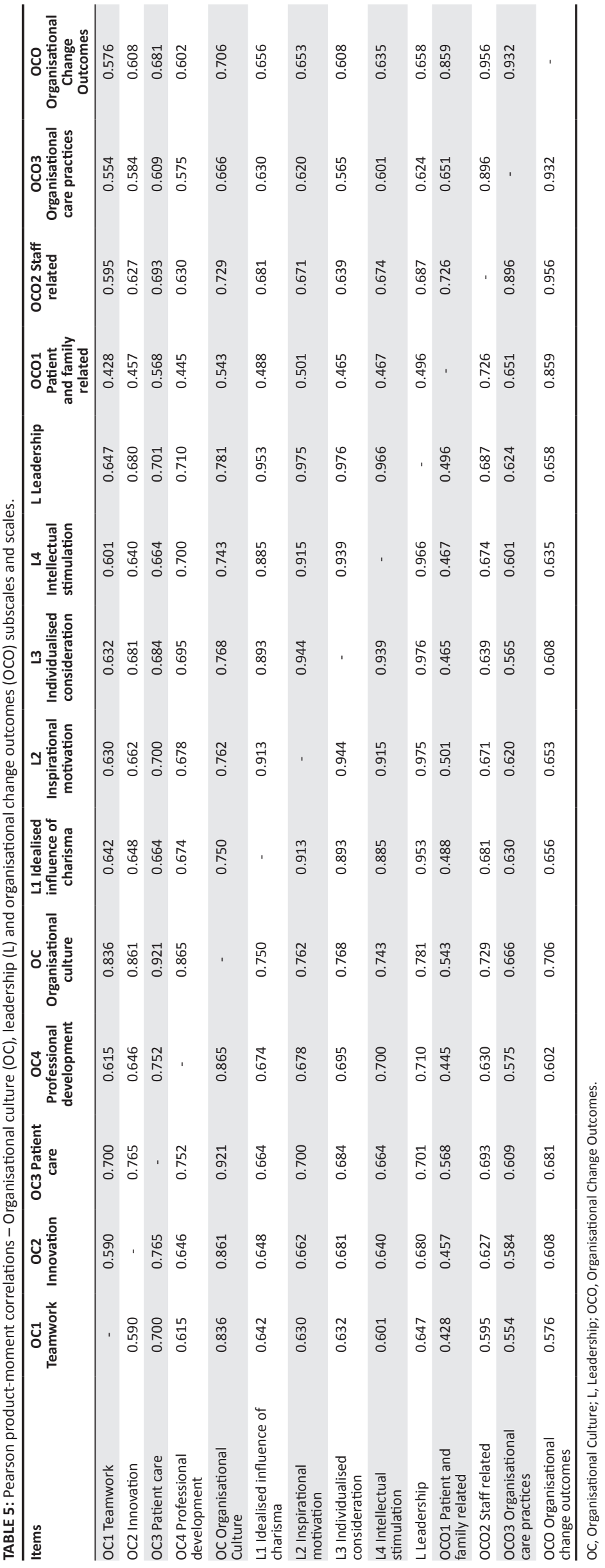


TABLE 6: Multiple linear regression analysis results.

\begin{tabular}{|c|c|c|c|c|c|}
\hline Item & Regression coefficients & Coefficients' std. errors & $t(125)$ & $p$-value & Values \\
\hline Intercept & 1.2707 & 0.2425 & 5.24 & $<0.0005$ & - \\
\hline Organisational Culture (OC) & 0.4835 & 0.0937 & 5.16 & $<0.0005$ & - \\
\hline Leadership (TL) & 0.1653 & 0.0618 & 2.67 & 0.008 & - \\
\hline Multiple $R$ & - & - & - & - & 0.730 \\
\hline Multiple $R^{2}$ & - & - & - & - & 0.533 \\
\hline Adjusted $R^{2}$ & - & - & - & - & 0.527 \\
\hline Regression test statistic & - & - & - & - & $F(2.125)=71.35$ \\
\hline Regression $p$-value & - & - & - & - & $p<0.0005$ \\
\hline Standard error of estimate & - & - & - & - & 0.418 \\
\hline
\end{tabular}

Standard error of estimate

$n=128$.

Regression formula: $\mathrm{OCO}=1.2707+0.4835 \mathrm{OC}+0.1653 \mathrm{TL}$

Regression Model = Dependent Variable: Organisational Change Outcomes (OCO); Independent Variables: Organisational Culture (OC) and Transformational Leadership (TL)

scored the lowest within this domain. A positive correlation $(r=0.706 ; p<0.05)$ exists between organisational culture and organisational change outcomes. Organisational culture is also a statistically significant predictor of organisational change outcomes $(\beta=0.5063 ; t=5.16 ; p=0.0005)$. The positive and significant correlation between organisational culture and organisational change outcomes therefore supports the acceptance of Hypothesis 2 in this study.

Organisational culture is directly linked to increased organisational effectiveness, performance and positive change outcomes (Hough et al., 2011). Furthermore, organisational culture has a direct and indirect influence on patient care delivery, cost-effective care, professionalism and professional development of healthcare professionals. An organisational culture that promotes teamwork, values and supports team members and their opinions and promotes excellence and quality patient care, enables change and allows for the implementation of change processes to be easier (Acar \& Acar, 2012). Carney (2011) found that patient care delivery that is aligned with positive value systems and strategic involvement is the most important organisational cultural factor in achieving excellence.

Innovation (the lowest scored subscale) is defined as the ability to develop and apply not only new products, processes or designs, but also new operation and business models (Gündo du, 2012). Innovation is viewed as an integral part of business strategy in boosting operational performance. Strong leadership, shared and clear objectives, task orientation, participative team spirit, increased patient safety, reflective team practices, active internal marketing, motivation and participation of personnel, lack of stress, and sufficient resources (financial, instrumental, and personal) all seem to be positively related to innovation in healthcare organisations (Gunday, Ulusoy, Kilic \& Alpkan, 2011).

Although transformational leadership and an organisational culture exist in the private intensive care units, the application of innovation might just enable the organisation to have a competitive advantage. It will attract and retain more customers, increase the business performance, and to become the leading intensive care unit in the country.

\section{Organisational change outcomes}

The results signify that organisational change outcomes were prevalent at the sampled intensive care units. The results from the regression analysis confirm the positive, significant relations between organisational culture, transformational leadership and organisational change outcomes $(R=0.730$; $\left.R^{2}=0.533 ; F=71.35 ; p<0.0005\right)$.

Jandaghi et al. (2009) found that transformational leadership, in combination with a positive culture, has a definite effect on organisational change, success and performance. They suggest that transformational leadership and culture are important factors in making behavioural and structural changes in an organisation, and are essential for survival in a competitive environment. Weiner (2009) asserts that an organisational culture with transformational leadership that embraces innovation, risk-taking, and learning, supports organisational readiness for change and enhances positive change outcomes. The existence of organisational change outcomes in the sampled intensive care units is viewed as positive, and can contribute towards achieving excellence in private healthcare.

A strong positive correlation was found between organisational culture and organisational change outcomes $(r=0.706 ; p<0.05)$. Strong positive correlations were also found between transformational leadership and organisational change outcomes $(r=0.658 ; p<0.05)$ and between organisational culture and transformational leadership $(r=0.781 ; p<0.05)$. Hypothesis 3 is therefore supported and accepted.

\section{Implications for practice}

Based on the results, it is recommended that transformational leaders in the intensive care units encourage intellectual stimulation, as it was the lowest scored domain. Intellectual stimulation can be developed and encouraged amongst team members in order to create an organisational culture of learning and innovation, thus contributing positively to change. The leaders can stimulate team members to think about traditional healthcare practices in a new way. They can also provide team members with new ways of solving challenging patient situations. Reflective discussion on 
patient scenarios and other management issues are methods to stimulate intellectual stimulation in the intensive care units. Applying these strategies to enhance intellectual stimulation can contribute towards achieving excellence in private intensive care units.

Innovation, which was the domain with the lowest score, needs to be encouraged and supported by leaders in the intensive care units. Leaders should be encouraged to sharpen and improve an organisational culture, thus avoiding traditional and ritualistic practices, but where innovation is encouraged. Short learning programmes can be developed and presented to managers in order to enhance their skills and knowledge regarding ways to improve innovative care practices. Leaders and managers can be taught how to embrace and facilitate reflective practice sessions in order to discuss care delivery and innovation in healthcare. Managers should introduce innovations, procedures and organisational processes that are new and better than those which are currently accepted or employed in a specific setting. These may include new therapies or diagnostic procedures that have proved their worth in well-designed clinical trials. Innovations may also include the use of clinical practice guidelines based on a systematic review of the scientific literature, a new procedure to prevent medication errors, or a checklist procedure in surgery. Innovation can also include new forms of care management of patients with disease conditions that are common in the intensive care units, for example, the management of blood glucose levels in a critically ill patient. The use of information technology, especially in the intensive care unit where monitoring systems, devices and machines are used, should be introduced as part of innovative practices.

\section{Limitations and recommendations for future research}

The geographical location of the intensive care units in the East London area necessitated the use of trained field workers to assist with data collection, which might have influenced the lower response rate from that area. Intensive care units are specialised, and generally deliver a small population size. However, a good overall response rate (72\%) was attained.

Similar research can be replicated in intensive care units in the public healthcare industry. Because the research was only conducted in private intensive care units, it is recommended that the study be replicated in public intensive care units and other healthcare units. Based on the results of the study, it is evident that an improvement in all of the investigated factors needs to be encouraged. An intervention study could be undertaken where innovative care practices are implemented and a post-test study is conducted, to explore its impact on organisational change outcomes.

\section{Conclusion}

The delivery of quality care in healthcare organisations, especially in intensive care units where critically ill patients are admitted, is of the utmost importance. Quality healthcare is dependent on continuous improvement and change. Leaders play an important role in creating such a culture of innovation as they create conditions for employees to think critically about existing practices and provide them with the right conditions to improve care practices and the quality of patient care. It is evident that transformational leadership and organisational culture are associated with desired change outcomes through teamwork, professional development, patient care, and innovation.

\section{Acknowledgements Competing interests}

This study was financially supported by the National Research Foundation (NRF) of South Africa for the grant, 87924. Any opinion, finding and conclusion or recommendation(s) expressed in this article is that of the author(s) and the NRF does not accept any liability in this regard.

\section{Authors' contributions}

P.J.J. (Nelson Mandela Metropolitan University) was the project leader. P.J.J. was responsible for the project design, collected, analysed and interpreted the data and made the conceptual contributions. A.W. (Nelson Mandela Metropolitan University) was responsible for the design of the questionnaire, and made conceptual contributions. D.V. (Nelson Mandela Metropolitan University) assisted in drafting the questionnaire, conducted the data analyses and assisted in interpreting and presenting the data.

\section{References}

Acar, A.Z., \& Acar, P. (2012). The effects of organisational culture and innovativeness on business performance in healthcare industry. Procedia Social and Behavioural Sciences, 58(2), 683-692. http://dx.doi.org/10.1016/j.sbspro.2012.09.1046

Alharbi, T.S.J., Olsson, L.E., Ekman, I., \& Carlström, E. (2014). The impact of organisational culture on the outcome of hospital care: After the implementation of person-centred care. Scandinavian Journal of Public Health, 42(1), 104-110. PMID: 23960157, http://dx.doi.org/10.1177/1403494813500593

Bass, B.M., \& Avoloi, B.J. (2000). MLQ multifactor leadership questionnaire technical report. Thousand Oaks: Sage Publication.

Bass, B., \& Riggio, R.E. (2006). Transformational Leadership. Mahwah: Lawrence Erlbaum.

Burns, N., \& Grove, S.K. (2013). The practice of nursing research: Appraisal, synthesis and generation of evidence (7th edn.). St Louis: Elsevier Saunders.

Caldwell, D.F., Chatman, J., O'Reilly, C.A., Ormiston, M., \& Lapiz, M. (2008), Implementing strategic change in health care system: The importance of leadership and change readiness. Health Care Management Review, 33(2), 124-133. PMID: 18360163, http://dx.doi.org/10.1097/01.HMR.0000304501.82061.e0

Care Quality Commission (CQC) (2011). Previous NHS staff surveys. Retrieved May 14, 2014, from http://www.cqc.org.uk/aboutcqc.howwedoit

Carney, M. (2011). Influence or organisational culture on quality of healthcare delivery. International Journal of Health Care Quality Assurance, 24(7), 523-539. PMID: 22204086, http://dx.doi.org/10.1108/09526861111160562

Casida, J., \& Pinto-Zipp, G. (2008). Leadership-organisational culture relationship in nursing units of acute care hospitals. Nursing Economics, 28(1), 7-15. PMID: 18389837.

Craig, J.V., \& Smyth, R.L. (2012). The evidence-based practice manual for nurses (3rd edn.). Elsevier: Churchill Livingstone.

Dorgan, S., Layton, D., Bloo, N., Homke, R., Sadun, R., \& Van Reenen, J. (2010). Management in health care: Why good practice really matters. Retrieved March 13, 2014, from http://cep.lse.ac.uk/textonly/new/research

DuBrin, A.J. (2013). Principles of Leadership (7th edn.). South-Western Cengage Learning. Cincinnati OH, USA.

Econex (2013). The South African Private Healthcare Sector: Role and contribution to the economy. South African Private Practitioner Forum and HealthMan. South Africa. 
Eisenbeiss, S.A., \& Boerner, S. (2013). A double-edged sword: Transformational leadership and individual creativity. British Journal of Management, 24(1), 54-68. $\mathrm{http}: / / \mathrm{dx}$.doi.org/10.1111/j.1467-8551.2011.00786.x

Garci'a-Morales, V.J., Llore'ns-Montes, F.J., \& Verdú-Jover, A.J. (2008). The effects of transformational leadership on organizational performance through knowledge and innovation. British Journal of Management, 19(4), 299-319. http://dx.doi. org/10.1111/j.1467-8551.2007.00547.x

Gilley, A., McMillian, H.S., \& Gilley, J.W. (2009). Organizational change and characteristics of leadership effectiveness. Journal of Leadership and Organisational Studies, 16(1), 38-47. http://dx.doi.org/10.1177/1548051809334191

Gunday, G., Ulusoy, G., Kilic, K., \& Alpkan, L. (2011). Effects of innovation types on firm performances. International Journal of Production Economics, 133(2), 662-676. http://dx.doi.org/10.1016/j.ijpe.2011.05.014

Gündoğdu, M.C. (2012). Re-thinking entrepreneurship, intrapreneurship and innovation: A multi-concept perspective. Procedia - Social and Behaviora Sciences, 41, 296-303. http://dx.doi.org/10.1016/j.sbspro.2012.04.034

Hough, J., Arthur, A., Thompson, J.R., Strickland III, A.J., \& Gamble, J.E. (2011). Crafting and executing strategy (2nd edn.). New York: McGraw-Hill.

Hsiao, H., Chang, J., \& Tu, Y. (2012). The influence of hospital organisational culture on organisational commitment among nursing executives. African Journal of Business Management, 6(44), 10888-10895.

Jandaghi, G., Martin, H.Z., \& Farjarmi, A. (2009). Comparing transformational leadership in successful and unsuccessful companies. International Journal of Social Studies, 4(3), 200-220.

Klopper, H.C., Coetzee, S.K., Pretorius, R., \& Bester, P. (2012). Practice environments, job satisfaction and burnout of critical care nurses in South Africa. Journal of Nursing Management, 20(5), 685-695. PMID: 22823225, http://dx.doi. org/10.1111/j.1365-2834.2011.01350.x

Korbangyang, S., \& Ussahawanitchakit, P. (2009). Change readiness and performance of health care service business in Thailand: Mediator role of service excellence, resource exploitation and business competitiveness. International Journal of Business research, 9(5), 109-124.

Kwahk, K.Y., \& Lee, J.N. (2008). The role of readiness for change in ERP implementation: Theoretical bases and empirical validation. Journal Information and Management, 45(7), 474-481. http://dx.doi.org/10.1016/j.im.2008.07.002

Malloy, T., \& Penprase, B. (2010). Nursing style and psychosocial work environment Journal of Nursing Management, 18(6), 715-725. PMID: 20840366, http://dx.doi. org/10.1111/j.1365-2834.2010.01094.x
Mitchell, G. (2013). Selecting the best theory to implement planned change. Nursing Management, 20(1), 31-37. PMID: 23705547, http://dx.doi.org/10.7748/ nm2013.04.20.1.32.e1013

Parmelli, E., Flodgren, G., Beyer, F., Ballie, N., Schaafsma, M.E., \& Eccles, M.P. (2011). The effectiveness of strategies to change organisational culture to improve healthcare performance: A systematic review. Implementation Science, 6, 33. http://www.implementationscience.com/content/6/1/33

Ramachandran, S. (2013). The significance of organisational development. MiddleEast Journal of Scientific Research, 16(12), 1912-1914.

Robbins, B., \& Davidhizar, R. (2007). Transformational leadership in healthcare today. The Health Care Manager, 26(3), 234-239. PMID: 17938591, http://dx.doi. org/10.1097/01.HCM.0000285014.26397.e7

Schein, E. (1997). Organisational culture and leadership. San Francisco: Jossey-Bass.

Scott, T., Mannion, R., Davies, H.T.O., \& Marshall, M.N. (2003). Implementing culture change in healthcare: Theory and practice. International Journal of Quality in HealthCare, 15(2), 111-118. PMID: 12705704, http://dx.doi.org/10.1093/intahc/ mzg021

Scott, I., \& Mazhindu, D. (2014). Statistics for healthcare professionals: An introduction (2nd edn.). London: Sage Publications.

Thakur, R., Hsu, S.H.Y., \& Fontenot, G. (2012). Innovation in healthcare: Issues and future trends. Journal of Business Research, 65(1), 562-569. http://dx.doi. org/10.1016/j.jbusres.2011.02.022

Tourangeu, A.E., \& McGilton, K. (2004). Measuring leadership practices of nurses using the leadership practice inventory. Nursing Research, 53(3), 182-189. PMID: 15167506, http://dx.doi.org/10.1097/00006199-200405000-00005

Urden, L., Stacy, K., \& Lough, M. (2014). Critical care nursing: Diagnosis and management (7th edn.). Missouri: Elsevier Mosby.

Weiner, B.J. (2009). A theory for organisational readiness for change. Implementation Science, 4(1), 4-67. http://dx.doi.org/10.1186/1748-5908-4-67

Werner, A., Bagraim, J., Cunningham, P., Pieterse-Landman, E., Potgieter, T., \& Viedge, C. (2012). Organisational behaviour. A contemporary South African perspective. Pretoria: Van Schaik Publishers.

Wong, C.A., \& Cummings, G.G. (2007). The relationship between nursing leadership and patient outcomes: A systematic review. Journal of Nursing Management, 15(5), 508-521. PMID: 17576249.

Yildirim, N., \& Birinci, S. (2013). Impacts or organisational culture and leadership on business performance: A case study acquisition. Procedia-Social and Behavioura Sciences, 75(3), 71-82. http://dx.doi.org/10.1016/j.sbspro.2013.04.009 